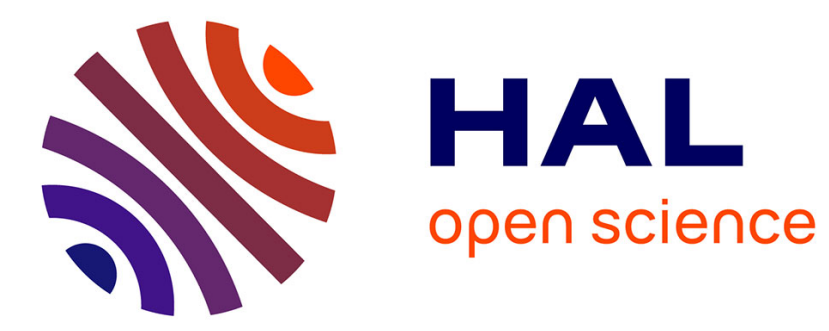

\title{
Pith: a new criterion for monitoring the architecture in Mediterranean pines
}

Fabien Buissart, Yves Caraglio, Philippe Borianne, Michaël Guéroult, Jimmy Le Bec, François Pailler, Michel Vennetier, Christophe Zilliox, Sylvie Sabatier

\section{- To cite this version:}

Fabien Buissart, Yves Caraglio, Philippe Borianne, Michaël Guéroult, Jimmy Le Bec, et al.. Pith: a new criterion for monitoring the architecture in Mediterranean pines. Trees - Structure and Function, 2015, 29 (6), pp.1827-1836. 10.1007/s00468-015-1264-6 . hal-01247952

\section{HAL Id: hal-01247952 \\ https://hal.science/hal-01247952}

Submitted on 23 Dec 2015

HAL is a multi-disciplinary open access archive for the deposit and dissemination of scientific research documents, whether they are published or not. The documents may come from teaching and research institutions in France or abroad, or from public or private research centers.
L'archive ouverte pluridisciplinaire HAL, est destinée au dépôt et à la diffusion de documents scientifiques de niveau recherche, publiés ou non, émanant des établissements d'enseignement et de recherche français ou étrangers, des laboratoires publics ou privés. 


\title{
Pith: a new criterion for monitoring the architecture in Mediterranean pines
}

\author{
Fabien Buissart ${ }^{1,2} \cdot$ Yves Caraglio $^{3} \cdot$ Philippe Borianne $^{3} \cdot$ Michaël Guéroult $^{3} \cdot$ Jimmy Le Bec $^{3} \cdot$ François \\ Pailler $^{3} \cdot$ Michel Vennetier $^{1} \cdot$ Christophe Zilliox $^{4} \cdot$ Sylvie-Annabel Sabatier $^{3}$
}

\section{Key-message}

Pith diameter is a good parameter to solve dating architecture problems.

\footnotetext{
Abstract

Plant architecture can be used to study plant development retrospectively thanks to time-dependent morphological markers, particularly those corresponding to the winter break in temperate regions. The Aleppo Pine and the Turkish Pine are polycyclic species, thus they usually develop several consecutive growth units per year, making it sometimes difficult to date them. In this study we show that keeping track of

F. Buissart ( $\square)$

e-mail: fabien.buissart@irstea.fr

Y. Caraglio

e-mail: yves.caraglio@cirad.fr

J. Le Bec

e-mail: jimmy.le_bec@cirad.fr

M. Vennetier

e-mail: michel.vennetier@irstea.fr

C. Zilliox

e-mail: christophe.zilliox.1@ulaval.ca

\section{SA. Sabatier}

e-mail: sylvie-annabel.sabatier@cirad.fr

${ }^{1}$ Irstea UR EMAX Ecosystèmes Méditerranéens et Risques, Centre d'Aix-en-Provence, 3275 route de Cézanne-cs40061, 13182 Aix-en-Provence Cedex 5, France

${ }^{2}$ Aix-Marseille Université, Jardin du Pharo-58, bd Charles Livon, 13284 Marseille Cedex 07, France

${ }^{3}$ CIRAD, UMR AMAP, 34398 Montpellier, France

${ }^{4}$ FFGG, Université Laval, Quebec, Canada
}

the pith diameter profile, in order to date each shoot, is an efficient method. The pith diameter is larger on the first growth unit than on the last growth unit of the year. Moreover, a pairwise comparison showed that the pith diameter undergoes a decrease along the annual shoot from the first growth unit to the last. As pith diameter decreases upwards the annual shoot, it can be used for dating. Pith diameter progresses from one year to another too: there is an increase in the early years of life, corresponding to the tree's establishment phase. Lastly, we found a positive relationship between the basal pith diameter of an annual shoot and its length. The variability around this relationship could reflect environmental conditions, especially climate conditions.

Keywords Pinus halepensis $\cdot$ Pinus brutia $\cdot$ Pith diameter . Plant architecture . Annual growth . Polycyclism

\section{Introduction}

There are two main ways of monitoring plant primary growth. The first consists of repeated measurements spread over time. However, this method would require decades of follow-up for large trees. The second method consists in retrospectively rebuilding plant development using morphological markers. Under contrasting climate seasons, such as temperate climates, seasonality can result in stops or slowdowns in the 
activity of plants (Sabatier and Barthélémy 1999; Heuret et al. 2006). Consequently, plants exhibit a succession of active and inactive growth phases. The portion of an axis elongated in an active phase is called a growth unit (GU) and the portion elongated in a year is called an annual shoot (AS). An annual shoot can be segmented into one GU (the AS is then monocyclic) or several GUs, the AS is then polycyclic. On this study, polycyclism and monocyclism has to be understood as defined in Barthélémy and Caraglio 2007: they should not be confused with prolepsis (branches develop right after the end of their organogenesis, then after the end of the elongation of their mother axis) and syllepsis (branches develop simultaneously with their mother axis). Depending on the species, the GU or the AS can be identified by external markers such as shorter internodes, scars from bud scales or branching (Thabeet et al. 2009; Girard et al. 2011; Taugourdeau et al. 2012). These markers can be used to mark out and date GUs and ASs and then allow the retrospective reconstruction of tree development in a non-destructive way. It provides information for studying ontogenetic growth trajectories and more generally temporal growth variability. It is therefore important to identify reliable markers for species of interest. Variations in stem pith size result from primary meristem activity: the alternance of extension and cessation periods. Flowering, branching, as well as shoot mortality, may be detectable from the pith size (Longuetaud and Caraglio, 2009). During plant life, endogenous trends in tree development have been revealed from the size and the morphology of annual shoots (Heuret et al. 2006, Guédon et al. 2007).

Longuetaud and Caraglio (2009) highlighted the fact that pith is a good marker of primary growth in Norway spruce (Picea abies (L.) Karst.). As pith diameter is larger at the base of the AS, it greatly helps in delimiting ASs. Although Norway spruce is monocyclic, whereas this study's species were polycyclic, we suspect that the pith diameter pattern observed for Norway spruce also holds for our species. Thus, pith diameter would help in dating GUs and identifying ASs in order to improve our understanding of polycyclism and to describe architecture.

Aleppo Pine (Pinus halepensis Mill.) and Turkish Pine (Pinus brutia Ten.) are two close species of great abundance (Nahal 1962; Nahal 1983; Nahal 1984) in the Mediterranean region. GUs of these species are relatively easy to identify thanks to scars left by bud scales (once fallen) at the bottom of the GU. Moreover, GUs usually end in a pseudo-whorl of branches: GUs are acrotonous (Leroy and Caraglio 2003; Barthélémy and Caraglio 2007; Caraglio et al. 2007; Millet 2012). As studied species are polycyclic, identifying GUs is not enough to detect ASs limits. For these species, the base of each AS can be identified by narrower and clustered scale scars and by longer GUs. However, those markers of AS limits are sometimes difficult to detect. Therefore, growth analysis of these species requires the use of tree rings to confirm AS dating. Using tree rings for dating gives rise to two issues: this method is destructive and is not easily performed at the top of the AS because the central ring is thinner.

Our hypothesis is that the morphological trends observed during annual growth and during tree life are reflected in variations in pith size as a proxy of meristem size. In our study we measured pith diameter in ASs of Aleppo Pines and Turkish Pines growing in the same plantation located in the South of France. We developed a method to standardize pith measurements and address the following questions. (i) Does the pith 
diameter decrease upwards the GU of a given AS? (ii) How can the pith diameter profile be used to analyse retrospectively the variability in primary tree growth?

\section{Materials and methods}

Study site

We worked in a comparative plantation (Project FAIR CT95-0097) of pine and cedar provenances at Aix-en-Provence $\left(43^{\circ} 30^{\prime} 34.87^{\prime \prime} \mathrm{N}, 5^{\circ} 24^{\prime} 23.95^{\prime \prime E}\right)$ in southeastern France. The stand consisted of a regular plantation $(1 \mathrm{~m} \times 1 \mathrm{~m})$ of 1 -year-old seedlings that had grown for a year in a nursery, in 1997. The pine provenances were Port-Cros (France) for Aleppo Pine and Anamur and Orhaneli (both in Turkey) for Turkish Pine. The climate was sub-humid Mediterranean with a cool winter (Ripert and Vennetier 2002). For the 19972011 period, the average rainfall was $580 \mathrm{~mm}$ per year and the mean annual temperature was $14.3^{\circ} \mathrm{C}\left(5^{\circ} \mathrm{C}\right.$ for the coldest month and $24^{\circ} \mathrm{C}$ for the hottest month), according to the MétéoFrance station at Aix-enProvence, located $2.5 \mathrm{~km}$ from the site. Figure 1 plots the annual De Martonne aridity index (de Martonne 1926) for the period of this study. It appeared that the stand had experienced contrasting years in terms of climate: the years 2002 and 2008 were humid, whereas 2004 to 2007 were semiarid. The study site was an alluvial terrace close to the Arc river with a permanent water table between one and two metres in depth, and it belonged to the best fertility class for Aleppo Pine on the French scale (Vennetier et al. 2010).

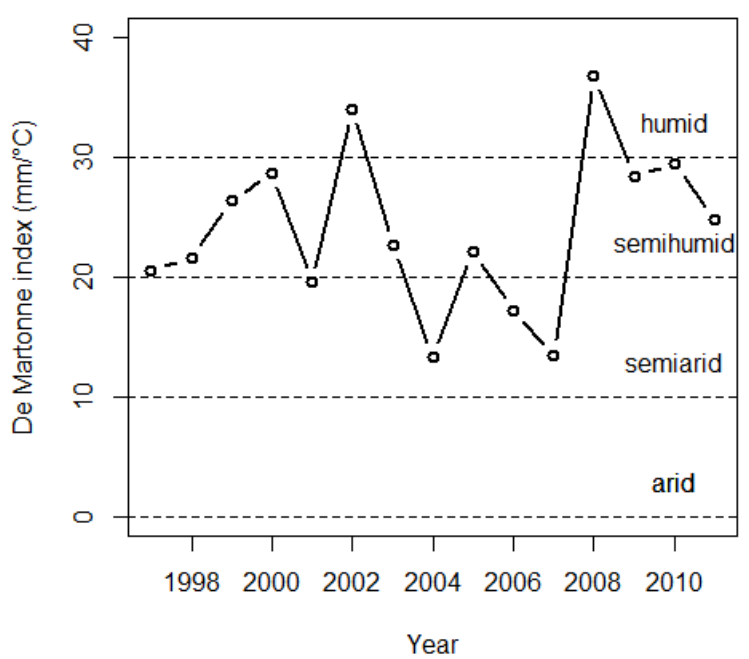

Figure 1 De Martonne aridity index during the years of the study

The annual De Martonne index is calculated as follows:

$\frac{P}{T+10}$ where $\mathrm{P}$ is the annual rainfall in $\mathrm{mm}$ and $\mathrm{T}$ the mean annual temperature in ${ }^{\circ} \mathrm{C}$. It appears that the years 2002 and 2008 where wet years, whereas 2004 to 2007 was a semiarid period.

\section{Data acquisition}

Eight Aleppo Pines and 12 Turkish Pines (6 from each provenance) were randomly selected in October 2011. The trees were cut down and we measured the length of each GU along the trunk in the field (GUs were located using pseudo-whorl branch positions). We also sampled a cross-section in the middle of each GU. The slices thus obtained were sanded with a grain of 60 and scanned at $300 \mathrm{dpi}$. Then we measured the pith diameter following these four steps (Figure 2):

1. Locating of the pith boundary along 4 radii (chosen manually, as orthogonal as possible including the largest and the smallest radius).

2. Conversion of the coordinates of the points into polar coordinates. 


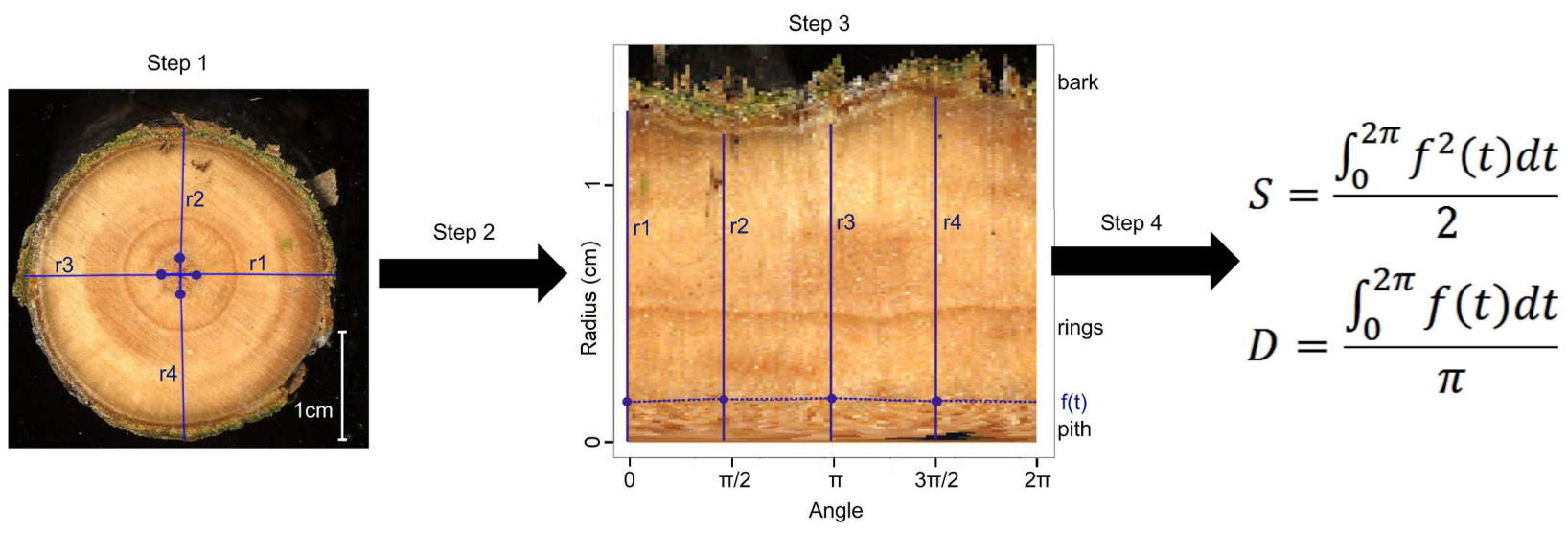

Figure 2 Pith diameter measuring method

The coordinates of the points are converted from Cartesian coordinate system (step 1) into the polar coordinate system (step 3). The center of the polar coordinate system is determined by the intersection of the four radiuses $(\mathrm{r} 1, \mathrm{r} 2, \mathrm{r} 3$ and $\mathrm{r} 4)$. The points are then joined by a linear interpolation (function $(t)$ : the distance of the pith limit as a function of the angle $t$ on the polar coordinate system) and the area $S$ and the diameter $D$ can be estimated by integral calculus.

3. Joining of all the points by linear interpolation in polar coordinates.

4. Estimation of the pith diameter by integration. From the scans, we counted the tree rings in order to date each $\mathrm{GU}$ and then determine to which AS they belonged.

\section{Data analysis}

All analyses were performed with $\mathrm{R}$ statistical software (version 2.15.1; R Development Core Team (2012)).

We only worked on ASs displaying at least 3 GUs. Indeed, at such a fertile site for these species, the AS develops its two first GUs simultaneously in spring (Girard et al. 2011). Up to 3 additional GUs are thus frequently observed on the ASs for these species at fertile sites. It is therefore likely that an AS with one or two GUs corresponded here to an accident (mechanical breaks, health problem, etc.). Then for each selected AS, we considered the pith diameter of the first $\left(D_{1}\right)$, the second $\left(D_{2}\right)$ and the last $G U\left(D_{L}\right)$. We also considered

\footnotetext{
$(i, j) \in\left\{D_{\text {max }}, D_{1}, D_{2}, D_{1-2}, D_{L}, D_{\text {min }}\right\}^{2}, \mathrm{n}_{\mathrm{i}>j}$ is the number of cases with $\mathrm{i}>j, \mathrm{n}_{\mathrm{i}=\mathrm{j}}$ the number of cases with $\mathrm{i}=\mathrm{j}$ and $\mathrm{n}$ the total number of observations: $n=n_{i>j}+n_{i=j}+n_{j>i}$. The minimum value is 0 ( $i$ always lower than $j$ ), the maximum is 1

( $i$ always higher than $j$ ) and $M(i, i)=0.5$.
} comparison for each AS the minimum pith diameter $\left(D_{\min }\right)$, the maximum pith diameter $\left(D_{\max }\right)$ and the maximum pith diameter of the first two GUs $\left(\mathrm{D}_{1-2}\right)$.

In order to test the difference between the pith diameter of the first $\mathrm{GU}$ and of the last GU, we calculated the confidence interval of the mean of the ratio $\mathrm{D}_{1} / \mathrm{D}_{\mathrm{L}}$ and of the ratio $\mathrm{D}_{1-2} / \mathrm{D}_{\mathrm{L}}$. If the confidence interval does not include 1 , then we concluded that $\mathrm{D}_{\mathrm{L}}$ was significantly different from the diameter of the first GU.

To complete the analysis, we performed a pairwise comparison between $\mathrm{D}_{\max }, \mathrm{D}_{1}, \mathrm{D}_{2}, \mathrm{D}_{1-2}, \mathrm{D}_{\mathrm{L}}$ and $\mathrm{D}_{\text {min. }} \mathrm{A}$ pairwise comparison enables the ranking of parameters from the smallest to the largest (Bradley and Terry 1952). To do so, we created a square matrix $M$ to compare the parameters in rows and in columns. The cell $M(i, j)$ reports the comparison between parameter $i$ and parameter $j$, (the calculation is explained in Equation 1). The value tested for parameter $i$ is the

$$
M(i, j)=\frac{n_{i>j}+0.5 n_{i=j}}{n}
$$
mparison 
mean of row $i$ : the higher the mean is, the better the rank of parameter $i$ is compared to the others.

Finally, we studied the average relation between the logarithm of $\mathrm{D}_{1-2}$ and the logarithm of annual shoot length performing a linear model ( $\operatorname{lm}$ function).

\section{Results}

The aim of this study was to show that pith diameter is a parameter that could be useful in monitoring plant architecture. Pith diameter is assumed to be larger at the base of the annual shoot and smaller at the top of the annual shoot.

Evolution of pith diameter along the AS: within-year variability

Table 1 gives the ratio of the pith diameter of the first two GUs $\left(D_{1}, D_{2}\right.$ and $\left.D_{1-2}\right)$ over $D_{L}$. Each value of the table is greater than 1 (the confidence interval does not include 1). A second noteworthy point is that for each species and each provenance, the ratios were at the same level (the confidence intervals overlapped). This shows that pith diameter was significantly greater for the first two GUs than for the last GU. This trend was the same for both species and for the three provenances.

Figure $3 \mathrm{a}$ plots $\mathrm{D}_{1}$ against $\mathrm{D}_{\max } .61 .5 \%$ of case points were on the dotted line $(\mathrm{x}=\mathrm{y})$, which means that
$D_{\max }$ was measured on the first GU. In the other cases, the points were under this line $\left(D_{1}<D_{\max }\right)$. For them, the average difference between $\mathrm{D} 1$ and $\mathrm{D}_{\max }$ was $0.41 \pm$ $0.43 \mathrm{~mm}$. Similarly, Figure $3 b$ represents $D_{L}$ against $\mathrm{D}_{\text {min }} .57 .1 \%$ of case points were on the dotted line $(\mathrm{x}=$ $y)$, which means that $\mathrm{D}_{\min }$ was measured on the last GU. In the other cases, points were above this line $\left(D_{L}>\right.$ $\left.\mathrm{D}_{\min }\right)$. For them, the average difference between $\mathrm{D}_{\mathrm{L}}$ and $\mathrm{D}_{\text {min }}$ was $0.35 \pm 0.30 \mathrm{~mm}$.

The frequency of ASs having a $D_{L}$ greater than $D_{1}$ was highly variable (Figure 4), with repeated low values from 2003 to 2007 corresponding to the drier period (Figure 1).

Table 2 gives the results of the pairwise comparison, ranking GUs in terms of their diameter and in order to study their affinity with the maximum and the minimum value. It shows that, for each species, the average GU rank was always $D_{1}>D_{2}>D_{L}$. $D_{1-2}$ was remarkably close to $\mathrm{D}_{\max }$, and $\mathrm{D}_{\mathrm{L}}$ was quite close to $\mathrm{D}_{\min }$.

Moreover, if the pith diameter was always larger for the first two GUs, then:

- $\quad M\left(D_{\text {max }}, D_{1-2}\right)=0.5$ (because $\left.D_{\max }=D_{1-2}\right)$

- $\quad M\left(D_{\max }, D_{1}\right)+M\left(D_{\max }, D_{2}\right)=1.5 \quad$ because for each AS, $D_{\max }$ was recorded either at the first $\mathrm{GU}$ or at the second

- $\quad M\left(D_{\text {max }}, D_{L}\right)=M\left(D_{\text {max }}, D_{\text {min }}\right)=1$

\begin{tabular}{llllr} 
Species & Provenance & $\mathbf{D}_{\mathbf{1}} / \mathbf{D}_{\mathbf{L}}$ & $\mathbf{D}_{2} / \mathbf{D}_{\mathbf{L}}$ & $\mathbf{D}_{\mathbf{1 - 2}} / \mathbf{D}_{\mathbf{L}}$ \\
\hline $\mathbf{A P}$ & $\mathbf{P C}$ & $1.60[1.29-1.90](68)$ & $1.45[1.18-1.71](68)$ & $1.68[1.39-1.98](68)$ \\
\hdashline & $\mathbf{O}$ & $1.80[1.58-2.00](66)$ & $1.56[1.36-1.76](66)$ & $1.86[1.65-2.08](66)$ \\
$\mathbf{T P}$ & $\mathbf{A}$ & $1.76[1.63-1.90](71)$ & $1.47[1.36-1.58](71)$ & $1.82[1.68-1.95](71)$ \\
& Whole & $1.78[1.65-1.90](137)$ & $1.51[1.40-1.62](137)$ & $1.84[1.72-1.96](137)$ \\
\hdashline$\ldots$ & $1.72[1.59-1.85](205)$ & $1.49[1.38-1.61](205)$ & $1.79[1.66-1.92](205)$ \\
\hline
\end{tabular}

Table 1 Average ratio of the pith diameter of the first GU to the pith diameter of the last GU

AP stands for Aleppo Pine, TP for Turkish Pine, PC for Port-Cros, O for Orhaneli and A for Anamur. The 5\% confidence level of the average is shown in square brackets. The number of records used for the calculation is indicated in brackets. Each ratio is greater than 1, which means that the first GU of the year has a larger pith diameter than the last GU of the year. 
a

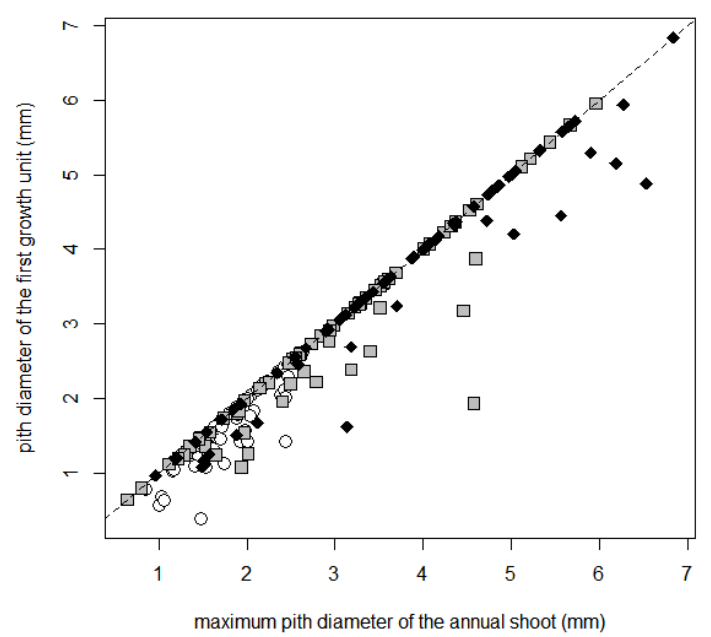

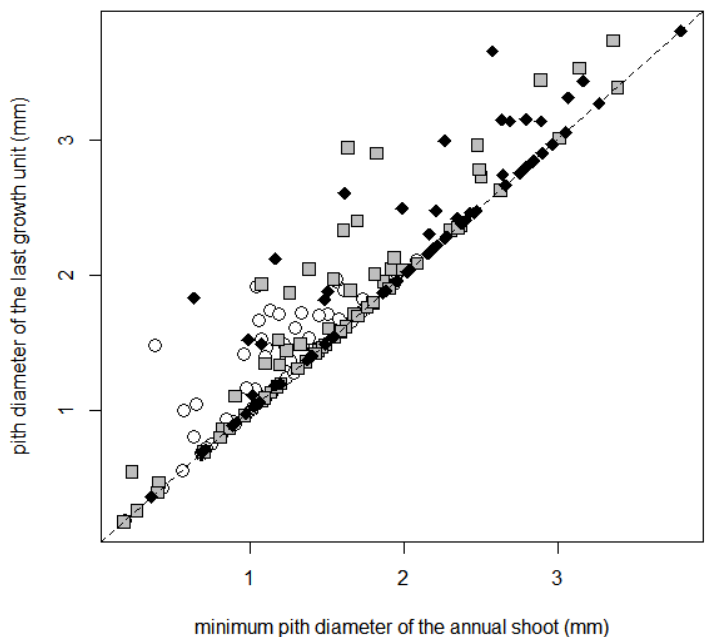

Figure 3 The diameter of the first (a) and of the last (b) growth unit of the annual shoot compared to the maximum (a) and to the minimum (b) pith diameter recorded for this annual shoot

The white circles stand for Aleppo Pine, the grey squares stand for Turkish Pine Orhaneli provenance and the black diamonds stand for Turkish Pine Anamur. The dotted line plots $\mathrm{y}=\mathrm{x}$ the maximum value for the pith diameter for fig. $3 \mathrm{a}$, the minimum value for fig. 3b. On both figures, all points are close to the line: the first GU of the year has the largest pith diameter (a) and the terminal GU of the year holds the thinnest pith diameter (b).

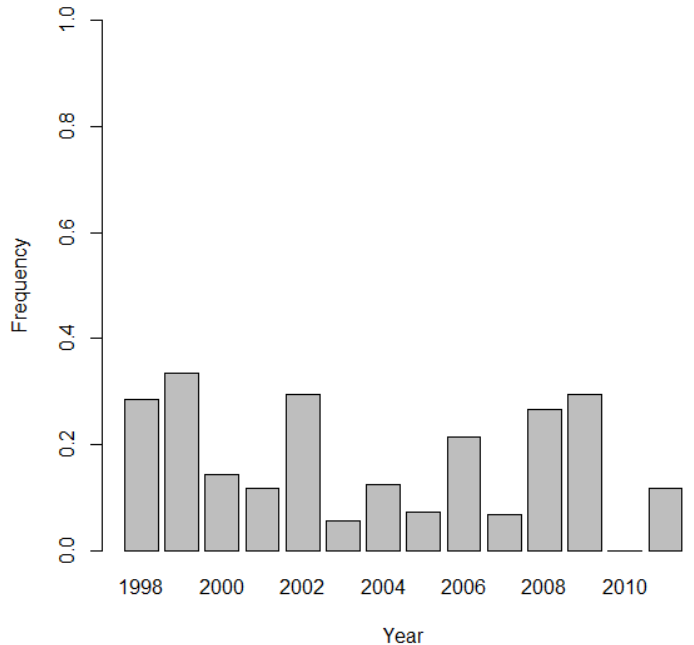

Figure 4 Distribution and frequency of records having $D_{L}$ higher than $D_{1}$

\begin{tabular}{llllllll} 
Species & Provenance & $\mathbf{D}_{\max }$ & $\mathbf{D}_{\mathbf{1}}$ & $\mathbf{D}_{\mathbf{2}}$ & $\mathbf{D}_{\mathbf{1 - 2}}$ & $\mathbf{D}_{\mathbf{L}}$ & $\mathbf{D}_{\min }$ \\
\hline $\mathbf{A P}$ & $\mathbf{P C}$ & 0.77 & 0.54 & 0.49 & 0.70 & 0.35 & 0.15 \\
\hdashline & $\mathbf{O}$ & 0.77 & 0.61 & 0.45 & 0.72 & 0.30 & 0.15 \\
$\mathbf{T P}$ & $\mathbf{T}$ & 0.76 & 0.65 & 0.46 & 0.73 & 0.25 & 0.15 \\
& $\mathbf{O}+\mathbf{T}$ & 0.76 & 0.63 & 0.46 & 0.73 & 0.27 & 0.15 \\
\hdashline $\mathbf{A P}+\mathbf{T P}$ & 0.77 & 0.60 & 0.47 & 0.72 & 0.30 & 0.15 \\
\hline
\end{tabular}

Table 2 Results of the pairwise comparison

AP stands for Aleppo Pine, TP for Turkish Pine, PC for Port-Cros, O for Orhaneli and A for Anamur. For each species and provenance, the values are ordered this way: $D_{1}>D_{2}>D_{L}$. The pith diameter decreases along the AS, $D_{1}$ is then close to $D_{\max }$ and $D_{L}$ close to $D_{\text {min }}$.

For the period from 2003 to 2007, the frequency of records having $D_{L}$ higher than $D_{1}$ is lower. This period corresponds to a semi-arid period. 
Author-produced version of the article published in Trees, 2015, 29 (6), 1827-1836.

The original publication is available at http://link.springer.com/

doi : $10.1007 / \mathrm{s} 00468-015-1264-6$

This gives a theoretical pairwise comparison value of:

increased from one year to the next. For the second step, $\frac{M\left(D_{\max }, D_{\max }\right)+M\left(D_{\max }, D_{1-2}\right)+M\left(D_{\max }, D_{1}\right)+M\left(D_{\max }, D_{2}\right)+M\left(D_{\max }, D_{L}\right)+M\left(D_{\max }, D_{\min }\right)}{6}=$ the basal pith diameter varied around a constant. For $\frac{0.5+1.5+0.5+1+1}{6}=0.75$ for $D_{\max }$. In our case, the value for Aleppo pine, the plateau started around 2001 and for $D_{\max }(0.76-0.77)$ and the value for $D_{1-2}(0.70-0.73)$ were close to the theoretical value.

Change in pith diameter along the trunk: between-year variability

Figure 5 plots the $\mathrm{D}_{1-2}$ profile according to the year. For each provenance and species, we identified two Turkish pine it started around 2003. This starting point for the second step needs to be compared with the appearance of sexual maturity. Indeed, the first cones noticed where in 2002 for Aleppo Pine and in 2005 for Turkish Pine. Thus, the plateau observed for the pith diameter profile appeared to coincide with sexual maturity.

steps. For the first step, the basal pith diameter
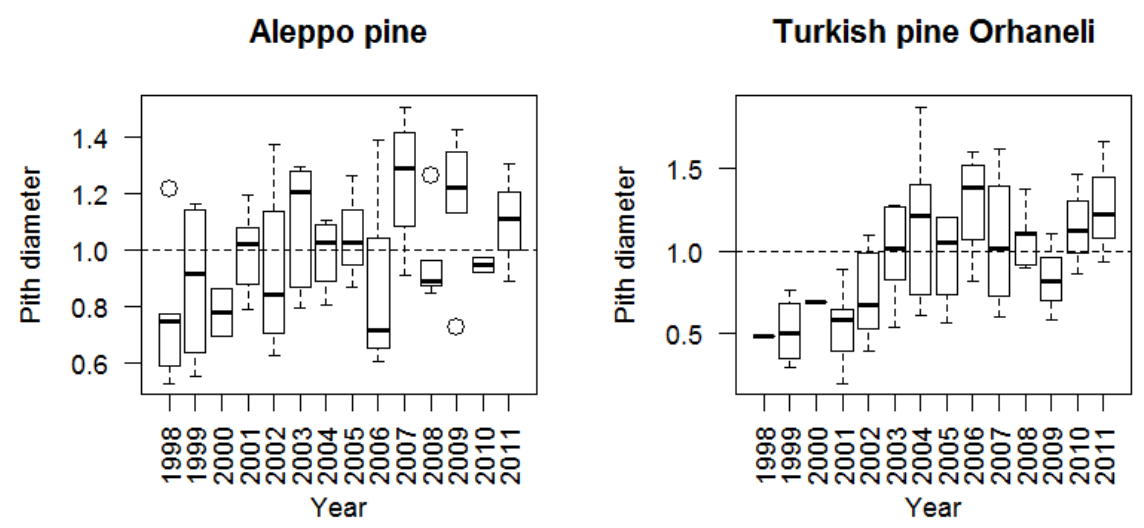

Turkish pine Anamur
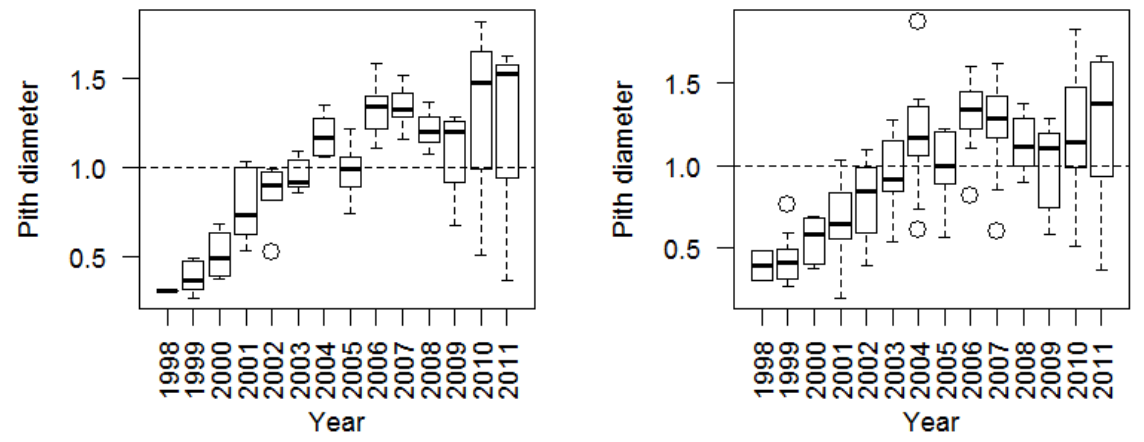

Figure 5 Basal diameter of the pith depending on the year

For each record, the basal pith diameter $\left(\mathrm{D}_{1-2}\right)$ is divided by the average basal pith diameter of the individual. For the early years of life, the pith diameter increases, and then varies around a constant. The increasing phase ended around 2001 (at the age of 6) for Aleppo pine and around 2003 (at the age of 8) for each provenance of Turkish pine. 
Relation between basal pith diameter and annual shoot length

Figure 6 plots the annual shoot length profile according to the year. Once again, we found the same pattern as that observed for the pith diameter profile: a first step corresponding to an increase and then a plateau. The transition between these two steps was around 2001 for Aleppo pine and around 2003 for Turkish pine too. It can be noted that the variations during the plateau for pith diameter were quite similar to those observed for annual shoot length.

Aleppo pine

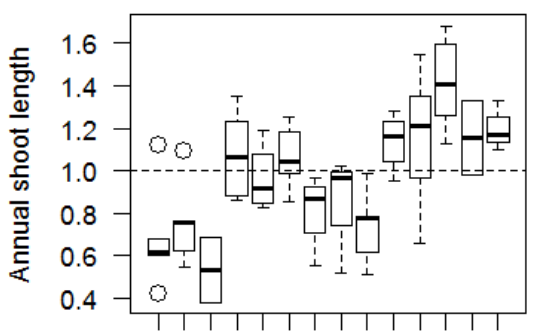

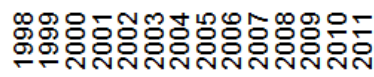

Year

Turkish pine Anamur

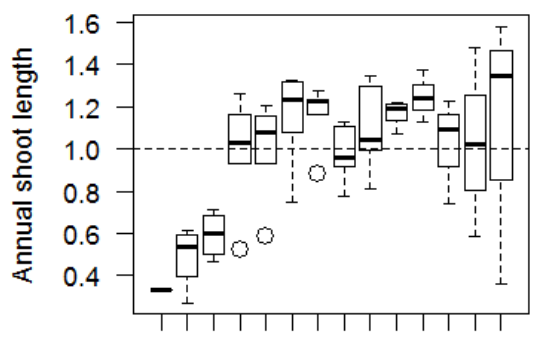

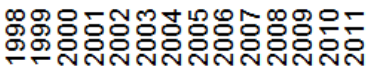

Year
Figure 7 shows the logarithm for annual shoot length according to the logarithm of $\mathrm{D}_{1-2}$. There seemed to be a linear correlation between these two parameters. Table 3 gives the parameters of the linear model fitted to explain the logarithm for annual shoot length depending on the logarithm for $\mathrm{D}_{1-2}$. The model satisfied the criteria in terms of $\mathrm{p}$-value, with $\mathrm{R}^{2}$ at around 0.5 : there was a clear correlation between these parameters, but residual variability remained high.

Turkish pine Orhaneli

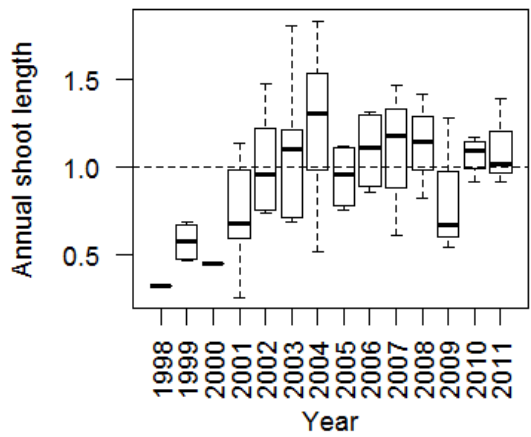

Turkish pine both provenances

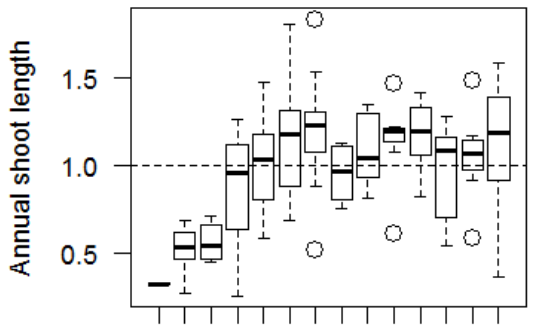

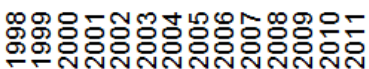

Year

Figure 6 Annual shoot length depending on the year

For each record, the annual shoot length is divided by the average shoot length of the individual. For the early years of life, the shoot length increases; this corresponds to the settlement stage. After the settlement phase, the shoot length varies around a constant; this correspond to the mature stage. The settlement phase ended around 2001 (at the age of 6) for Aleppo pine and around 2003 (at the age of 8) for each provenance of Turkish pine. 


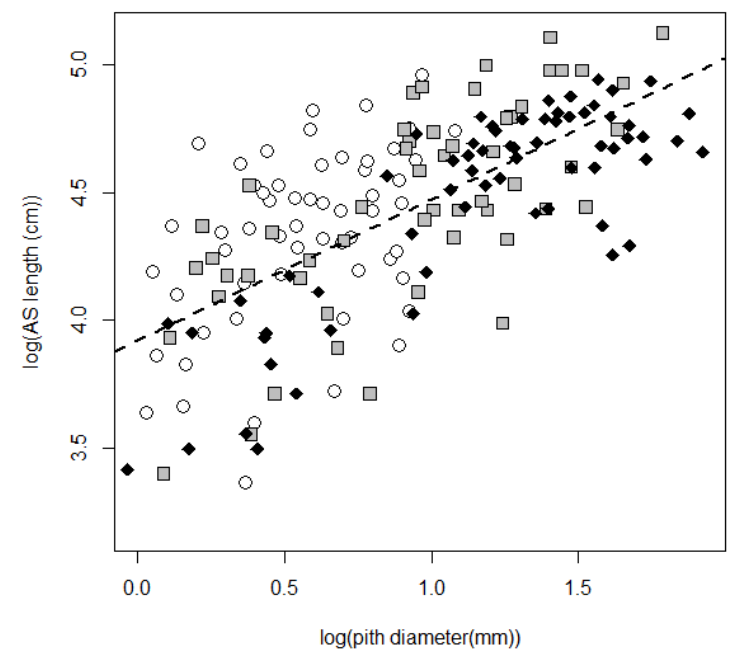

Figure 7 Logarithm of annual shoot length according to logarithm of pith diameter.

The white circles stand for Aleppo Pine, the grey squares stand for Turkish Pine Orhaneli provenance and the black diamonds stand for Turkish Pine Anamur. The line plots the linear model: the AS length increase with $\mathrm{D}_{\text {. }}$.

\begin{tabular}{lrrrrr} 
& model & Intercept & $\log \left(\mathbf{D}_{\mathbf{1 - 2}}\right)$ & $\begin{array}{l}\text { Degrees of } \\
\text { freedom }\end{array}$ & $\mathbf{R}^{\mathbf{2}}$ \\
\hline value & & 3.918 & 0.553 & 177 & 0.4959 \\
p-value & $<2 \mathrm{e}-16$ & $<2 \mathrm{e}-16$ & $<2 \mathrm{e}-16$ & & \\
\hline
\end{tabular}

Table 3 Parameters of the linear model predicting the logarithm of annual shoot length

The model satisfies the criteria ( $\mathrm{p}$-value for the parameters and model below $0.05)$. $\mathrm{R}^{2}$ is around 0.5 : this model explains almost half of the total variance.

Figure 8 shows the distribution of the residuals depending on the year of the AS. For the three provenances, the residuals were mainly below 0 before 2001. They all showed a peak between 2001 and 2003 or 2004 followed by a trough lasting two or three years from 2004 for Aleppo pine and 2005 for Turkish pine, with the decline being limited for the Anamur

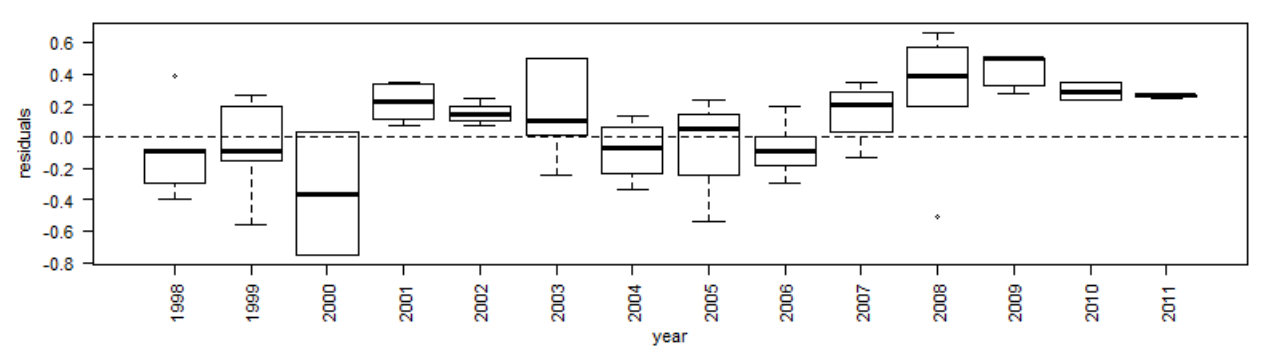

Turkish pine Orhaneli

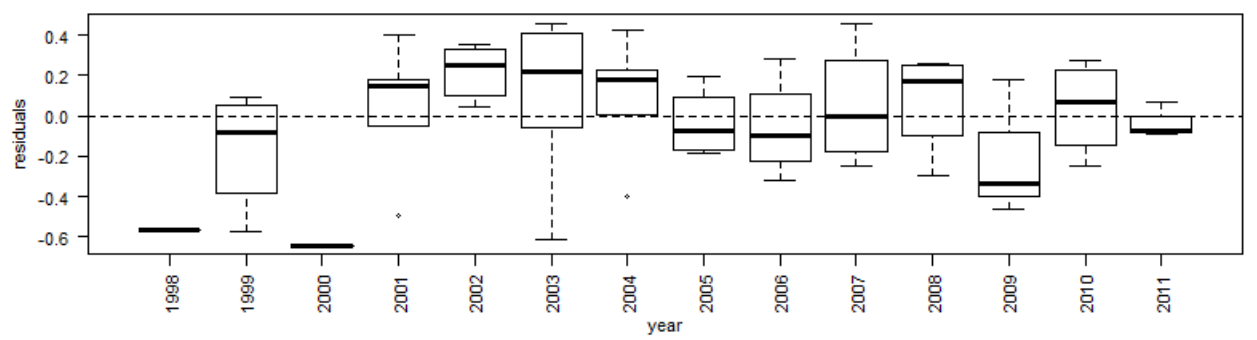

Turkish pine Anamur

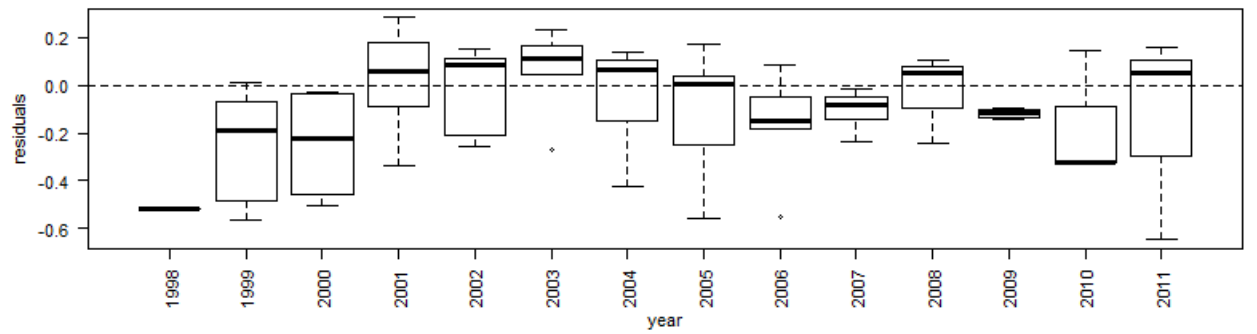

Figure 8 Distribution of the residuals of the relation between the annual shoot length and the pith diameter of the first growth unit

The variability of the distribution of the residuals of the relation between annual shoot length and initial pith diameter is reduced when the residuals are aggregated by year. This shows that the relation between $\mathrm{D}_{1}$ and AS length is at some point driven by the year. 
provenance. All provenances peaked again in 2007 and 2008 before declining up to 2011. Of the three provenances, residual interannual variations were more confined around 0 for Anamur and maximum for Aleppo pine.

\section{Discussion}

Pith diameter is a good marker for dating growth units In order to monitor architecture retrospectively via primary growth, we showed that measuring the pith diameter profile provides useful information. On average, the first $\mathrm{GU}$ of the year exhibited the largest pith diameter of the AS. The pith diameter measured for the last GU of the year was often close to the minimum pith diameter of the AS. These results show that the pith diameter generally decreased along the AS from the base to the top of the AS, in accordance with our hypothesis and the results of Longuetaud and Caraglio (2009) for Norway spruce. Although there were frequent exceptions for individual trees and years, this decrease could reflect the fact that GUs are preformed in the bud. The first GUs of an AS elongates at the beginning of spring (Caraglio et al. 2007; Girard et al. 2011). The preformation of these GUs occurs from the middle of the autumn of the previous year to winter (Girard et al. 2011). During organogenesis, there is usually no drought stress and little or no primary and secondary growth. Soil nutrients, plant reserves and water are therefore fully available for preformation: the meristem diameter can be large. Conversely, the following $\mathrm{GU}$ is preformed either at the end of spring, simultaneously with active primary and secondary growth, or during summer when water stress is usually strong in the Mediterranean region. Moreover, during summer both species are still active, allocating resources to needle growth. Thus competition must be strong for resources between bud formation and other growth processes. Years with a $\mathrm{D}_{\mathrm{L}}$ higher than $\mathrm{D}_{1}$ may correspond to years with low water stress in spring and summer. This is consistent with the lower percentage of ASs having a $D_{L}$ higher than $D_{1}$ in the driest years (Figure 4). Indeed, the spring or summer drought was more severe for these years.

At the fertile study site with a water table available at depth at least in good years, the summer conditions may sometimes have been sufficient for a high level of activity. This resulted in a high polycyclism rate $(3.40$ for Aleppo pine and 3.84 for Turkish pine). Late flushes, when more than 3 were found in an AS, appeared at the end of summer or the beginning of autumn when rainfall resumed and other growth processes were less active than in spring. The fact that $\mathrm{D}_{\mathrm{L}}$ was not that close to $\mathrm{D}_{\text {min }}$ (compared to the closeness between $\mathrm{D}_{1}$ and $\mathrm{D}_{\max }$ ) was consistent with more variable conditions during organogenesis, related to the number of GUs of the AS and climate variability. Together with this high polycyclism rate, cones were borne by the last GU of some ASs and developed in winter. Cones are supposed to be borne by the first GU of the year (Millet 2012) and always develop in spring. This suggests that at our site, and thanks to warm autumns, the conditions were favourable enough to enable a GU, scheduled for the following year, to start its elongation at the end of the autumn or in winter. Such a GU should have a larger pith diameter than the previous GU. This confirms the observation in the same region of an increasing proportion of shoots from Aleppo pine starting their growth in autumn to finish it in spring, in the last decade (Vennetier et al. 2011).

Finally, the change in pith diameter along the AS ought to be the signature of the difference in GU preformation conditions. This could help in dating GUs 
in addition to the usual markers such as scale scars, cones or branches, which can be missing or difficult to read, and when cones appear on several successive GUs. It can also be helpful if other criteria such as the relative length of the first GU of the year and the last GU of the previous year are not clear, and when the first ring of the last GU is almost invisible (Figure 9).

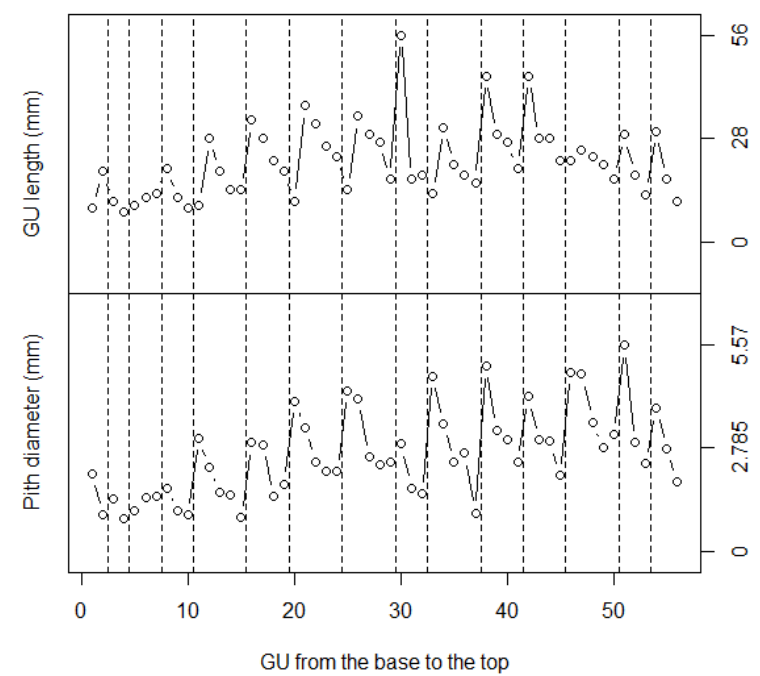

Figure 9 Help of pith diameter profile in dating GU

The upper chart plots the GU length, the other plots the pith diameter profile for the same individual. The vertical dotted lines correspond to the limit between two ASs. Each peak is assumed to be the first GU of a year. The pith diameter enables a reduction in dating error (for instance the GU length would indicate the last GU of the year for the $20^{\text {th }}$ $\mathrm{GU}$, but the pith diameter corresponds to the first GU).

Shoot length is correlated to the pith diameter of the first $G U$

Our study showed a correlation between the initial pith diameter and the total AS length (Figure 7). This relation may partly reflect the fact that the first GU corresponded to the elongation of the shoot preformed in the bud. Thus before elongation, the meristem had a definite number of phytomers, which determined potential growth. If conditions are unfavourable during year $n$, the bud for year $n+1$ will have low potential for length growth, due to a reduced number of phytomers, and a smaller pith diameter also predetermined by the same poor conditions. This hypothesis is consistent with the delayed response of tree architectural development and shoot length growth to the climate for Aleppo pine (Girard et al. 2010; Girard et al. 2011), but also for Scots pine (Pinus sylvestris L.) in the same region (Vila et al. 2001) and in other countries (Mäkinen 1998). On the other hand, the elongation of preformed phytomers also depended on the climate of the AS growth year. Under stressful conditions, the shoot may not reach the potential length (residuals below 0 in figure 8), and under favourable conditions the shoot optimizes the potential length (residuals above 0). Moreover, when an AS was composed of more than two flushes, the third and later flush were probably determined during this AS elongation so that the final AS length depended on both the previous and current year. This explains why the correlation between the proximal pith diameter and shoot length was quite weak, although significant.

The annual distribution of the residuals for the relation linking pith diameter and annual shoot length (Figure 8 ), as well as their high variability within each year, highlights the interaction between the current and previous year in shoot length in this correlation. For both species and all provenances, from 1998 to 2000, the residuals were below 0 . This corresponds to the juvenile phase: the plants mainly develop their roots and there is no competition so secondary growth is promoted before primary growth (Schenk and Jackson 2002). During the mature phase, the trees endured contrasting years: 2003 to 2007 were dry years whereas 2002 and 2008 were wet. In 2008, the high mean value of residuals corresponded to low pith diameter values, 
induced by a very bad year in 2007 , along with a long shoot, promoted by the favourable climate, which allowed good elongation of preformed GUs and the development of additional GUs. Low values over the 2004-2007 period may have been due to the significant reduction in polycyclism over those years (Girard et al. 2011), holding back shoot length, and leading to weak elongation of preformed GUs.

Similarly, it was possible here to characterize the juvenile phase and the mature phase from the pith diameter profile according to the year. Indeed, in the first years of studying the trees, corresponding to the establishment phase, the initial pith diameter increased with time together with the annual shoot length. Then a plateau occurred, corresponding to a more mature tree phase. Thus a wood cross-section contains information about primary growth with the pith diameter, and secondary growth with the tree rings.

\section{Conclusion}

We showed that the pith diameter generally decreases along the annual shoot, as a probable response to environmental conditions during bud formation: the first growth units of an annual shoot are preformed in the bud during the autumn of the previous year under favourable conditions, whereas the last growth units are often preformed under stressful conditions, and compete with the elongation of the previous growth unit. This is consistent with the fact that under Mediterranean climate, summer is dry and autumn is wet. This could be different in a different type of climate. This phenomenon can be very useful for retrospectively measuring the architecture on Aleppo pine and Turkish pine. Pith diameter measurements can also be nondestructive through the use of X-ray techniques. However, there were quite a lot of exceptions to the general trend. The dates and conditions of GU morphogenesis in buds are not accurately known. They greatly depend on site conditions and branch vigour leading to highly variable polycyclism patterns and numbers of growth units. This study therefore needs to be repeated at less fertile sites and with a simultaneous study of bud content over the year. We also found that the annual shoot length was correlated to the proximal pith diameter, although many interactions between the climate of two successive years may weaken this correlation

The pith diameter profile along annual shoots is thus able to provide useful information about environmental conditions and tree growth processes. It could also be used to improve the analysis of climate change impacts on plant development, by factoring out some age-related variations in tree growth such as the drift in axis vigour. It can help the retrospective analysis of tree architecture to provide longer chronosequences.

Retrospective analysis provides information for forest management (Caraglio et al. 2007), for carbon partitioning within a tree (Godin 2000, Rutishauser et $\mathrm{al} ; 2011)$ and for dating tree populations (Zalmea et al. 2012).

\section{Acknowledgements}

This work was supported by funds from the French Agricultural Ministry and the Mixed Technology Network on the adaptation of forests to climate change (RMT AFORCE) through the Botany and Computational Plant Architecture, joint research unit (UMR AMAP), National Institute for Science Research and Technology for Environment and Agriculture (Irstea) and the Provence-Alpes-Côte d'Azur region ( $\mathrm{PhD}$ grant). The authors sincerely thank the Milles departmental nursery and its staff, Raphaël Manlay from AgroParisTech-Montpellier and the English correctors of CIRAD.

\section{Conflict of interest}

The authos declare that they have no conflict of interest 


\section{Author contribution statement}

Fabien Buissart: data acquisition (on field and on lab), analysis and writing. Yves Caraglio: supervising and writing. Philippe Borianne: analysis. Michaël Guéroult: project initiation and data acquisition (on field and on lab). Jimmy Le Bec: analysis. François Pailler: project initiation and data acquisition (on field and on lab). Michel Vennetier: supervising and writing. Christophe Zilliox: analysis. Sylvie-Anabel Sabatier: supervising and writing.

\section{References}

Barthélémy D, Caraglio Y (2007) Plant architecture: a dynamic, multilevel and comprehensive approach to plant form, structure and ontogeny. Ann Bot 99:375-407.

Bradley RA, Terry ME (1952) Rank analysis of incomplete block designs: I. The method of paired comparisons. Biometrika 324-345.

Caraglio Y, Pimont F, Rigolot E (2007) Pinus halepensis Mill. Architectural analysis for fuel modelling. Proceedings of the international workshop MEDPINE. p 43e59

De Martonne E (1926) L'indice d'aridité. Bull Assoc Géographes Fr 3:3-5.

Girard F, Vennetier M, Ouarmim S, et al. (2011) Polycyclism, a fundamental tree growth process, decline with recent climate change: the example of Pinus halepensis Mill. in Mediterranean France. Trees 25:311-322.

Girard F, Vennetier M, Ouarmim S, et al. (2010) Fundamental tree growth processes severely suffer from water stress. The example of Pinus halepensis Mill. in South-eastern France. EGU General Assembly Conference Abstracts. p 4543

Godin C (2000) Representing and encoding plant architecture: a review. Ann For Sci 57:413-438

Guédon Y, Caraglio Y, Heuret P, Lebarbier E, Merdieu $\mathrm{C}$ (2007) Analyzing growth components in trees. J Theor Biol 248:418-447

Heuret P, Meredieu C, Coudurier T, et al. (2006) Ontogenetic trends in the morphological features of main stem annual shoots of Pinus pinaster (Pinaceae). Am J Bot 93:1577-1587.

Leroy C, Caraglio Y (2003) Effect of tube shelters on the growth of young Turkish pines (Pinus brutia Ten., Pinaceae). Ann For Sci 60:539547.

Longuetaud F, Caraglio Y (2009) Pith: a marker of primary growth in Picea abies (L.) Karst. Trees 23:325-334.

Mäkinen H (1998) The suitability of height and radial increment variation in $<$ i $>$ Pinus sylvestris $<\mathrm{i}>$ (L.) for expressing environmental signals. For Ecol Manag 112:191-197.

Millet J (2012) L'architecture des arbres des régions tempérées: son histoire, ses concepts, ses usages. Éditions MultiMondes, Québec

Nahal I (1962) Le Pin d'Alep (Pinus halepensis Mill.). Étude taxonomique, phytogéographique, écologique et sylvicole.

Nahal I (1983) Pinus brutia subsp. brutia. Part 1.

Nahal I (1984) Pinus brutia subsp. brutia. Part 2.

Rutishauser E, Barthe'le'my D, Blanc L, Nicolini EA (2011) Crown fragmentation assessment in tropical trees: Method, insights and perspectives. For Ecol Manag 261:400-407

Ripert C, Vennetier M (2002) Guide technique du forestier méditerranéen français, chapitre 2 bis : évaluation des potentialités forestières.

Sabatier S, Barthélémy D (1999) Growth dynamics and morphology of annual shoots, according to their architectural position, in young Cedrus atlantica (Endl.) Manetti ex Carrière (Pinaceae). Ann Bot 84:387-392.

Schenk HJ, Jackson RB (2002) The global biogeography of roots. Ecol Monogr 72:311328.

Taugourdeau O, Dauzat J, Griffon S, et al. (2012) Retrospective analysis of tree architecture in silver fir (Abies alba Mill.): ontogenetic trends and responses to environmental variability. Ann For Sci 69:713-721. 
Author-produced version of the article published in Trees, 2015, 29 (6), 1827-1836.

The original publication is available at http://link.springer.com/

doi : $10.1007 / s 00468-015-1264-6$

Team, R. Development Core. R (2012) R: A language and environment for statistical computing. $\mathrm{R}$ Foundation for Statistical Computing, Vienna, Austria

Thabeet A, Vennetier M, Gadbin-Henry C, et al (2009) Response of Pinus sylvestris L. to recent climatic events in the French Mediterranean region. Trees 23:843-853.

Vennetier M, Girard F, Didier C, et al (2011) Adaptation phénologique du pin d'Alep au changement climatique.

Vennetier M, Ripert C, Brochiéro F, et al (2010) Évaluation de la croissance du pin d'Alep en région méditerranéenne française.

Vila B, Nicault A, Vennetier M (2001) Influence de la densité des peuplements sur la croissance en hauteur et radiale de Pinus sylvestris L. en région méditerranéenne française. For Méditerranéenne 22:65-74.

Zalamea P-C, Heuret P, Sarmiento C, et al (2012) The genus Cecropia: a biological clock to estimate the age of recently disturbed areas in the Neotropics. PloS One 7:e42643 